NASA/TM-2003-212584

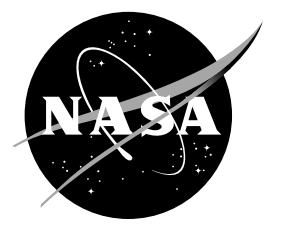

Significance of Strain in Formulation in Theory of Solid Mechanics

Surya N. Patnaik

Ohio Aerospace Institute, Brook Park, Ohio

Rula M. Coroneos and Dale A. Hopkins

Glenn Research Center, Cleveland, Ohio 
Since its founding, NASA has been dedicated to the advancement of aeronautics and space science. The NASA Scientific and Technical Information (STI) Program Office plays a key part in helping NASA maintain this important role.

The NASA STI Program Office is operated by Langley Research Center, the Lead Center for NASA's scientific and technical information. The NASA STI Program Office provides access to the NASA STI Database, the largest collection of aeronautical and space science STI in the world. The Program Office is also NASA's institutional mechanism for disseminating the results of its research and development activities. These results are published by NASA in the NASA STI Report Series, which includes the following report types:

- TECHNICAL PUBLICATION. Reports of completed research or a major significant phase of research that present the results of NASA programs and include extensive data or theoretical analysis. Includes compilations of significant scientific and technical data and information deemed to be of continuing reference value. NASA's counterpart of peerreviewed formal professional papers but has less stringent limitations on manuscript length and extent of graphic presentations.

- TECHNICAL MEMORANDUM. Scientific and technical findings that are preliminary or of specialized interest, e.g., quick release reports, working papers, and bibliographies that contain minimal annotation. Does not contain extensive analysis.

- CONTRACTOR REPORT. Scientific and technical findings by NASA-sponsored contractors and grantees.
- CONFERENCE PUBLICATION. Collected papers from scientific and technical conferences, symposia, seminars, or other meetings sponsored or cosponsored by NASA.

- SPECIAL PUBLICATION. Scientific, technical, or historical information from NASA programs, projects, and missions, often concerned with subjects having substantial public interest.

- TECHNICAL TRANSLATION. Englishlanguage translations of foreign scientific and technical material pertinent to NASA's mission.

Specialized services that complement the STI Program Office's diverse offerings include creating custom thesauri, building customized databases, organizing and publishing research results ... even providing videos.

For more information about the NASA STI Program Office, see the following:

- Access the NASA STI Program Home Page at http://www.sti.nasa.gov

- E-mail your question via the Internet to help@sti.nasa.gov

- Fax your question to the NASA Access Help Desk at 301-621-0134

- Telephone the NASA Access Help Desk at 301-621-0390

- Write to:

NASA Access Help Desk

NASA Center for AeroSpace Information 7121 Standard Drive

Hanover, MD 21076 
NASA/TM-2003-212584

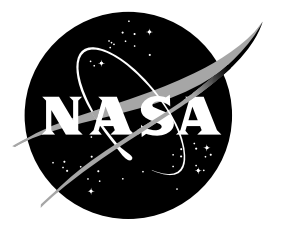

\section{Significance of Strain in Formulation in Theory of Solid Mechanics}

Surya N. Patnaik

Ohio Aerospace Institute, Brook Park, Ohio

Rula M. Coroneos and Dale A. Hopkins

Glenn Research Center, Cleveland, Ohio

National Aeronautics and

Space Administration

Glenn Research Center 
This work was sponsored by the Low Emissions Alternative Power Project of the Vehicle Systems Program at the NASA Glenn Research Center.

Available from

NASA Center for Aerospace Information 7121 Standard Drive

Hanover, MD 21076
National Technical Information Service 5285 Port Royal Road Springfield, VA 22100

Available electronically at http:/ /gltrs.grc.nasa.gov 


\title{
Significance of Strain Formulation in Theory of Solid Mechanics
}

\author{
Surya N. Patnaik \\ Ohio Aerospace Institute \\ Brookpark, Ohio 44142 \\ Rula M. Coroneos and Dale A. Hopkins \\ National Aeronautics and Space Administration \\ Glenn Research Center \\ Cleveland, Ohio 44135
}

\begin{abstract}
The basic theory of solid mechanics was deemed complete circa 1860 when St. Venant provided the strain formulation or the field compatibility condition. The strain formulation was incomplete. The missing portion has been formulated and identified as the boundary compatibility condition (BCC). The BCC, derived through a variational formulation, has been verified through integral theorem and solution of problems. The BCC, unlike the field counterpart, do not trivialize when expressed in displacements. Navier's method and the stiffness formulation have to account for the extra conditions especially at the inter-element boundaries in a finite element model. Completion of the strain formulation has led to the revival of the direct force calculation methods: the Integrated Force Method (IFM) and its dual (IFMD) for finite element analysis, and the completed Beltrami-Michell formulation (CBMF) in elasticity. The benefits from the new methods in elasticity, in finite element analysis, and in design optimization are discussed. Existing solutions and computer codes may have to be adjusted for the compliance of the new conditions. Complacency because the discipline is over a century old and computer codes have been developed for half a century can lead to stagnation of the discipline.
\end{abstract}

\section{Introduction}

The theory of solid mechanics is formulated through a set of formidable mathematical equations. An engineer may select an appropriate subset to solve a particular problem. An error in the solution is normally attributed either to equation complexity, or to a deficiency in the model. But rarely the completeness of the basic theory is questioned because it was presumed complete, circa 1860, when St. Venant provided the strain formulation. This conclusion is not justified because incompleteness has been detected in the strain formulation. Research is in progress to alleviate the deficiency in the theory of solid mechanics. Benefits from the use of the completed strain formulation are being shown in continuum elasticity, ${ }^{1-6}$ in finite element analysis, ${ }^{7-25}$ and in design optimization. ${ }^{26-36}$

The theory of strengths of materials began with the cantilever experiment conducted by Galileo in 1632. ${ }^{37}$ Several decades later the stress $(\sigma)$-strain $(\varepsilon)$ law $\{\sigma\}=[\kappa]\{\varepsilon\}$ was formulated and interpreted by Hooke (1635-1703), Young (1773-1829), and Poisson (1781-1840). The material 
law contained the genus of analysis. The constraint imposed on stress became the stress formulation. Likewise, the condition on the strain became the strain formulation. The stress and strain formulations along with the material matrix $[\kappa]$ are sufficient for the determination of the stress state in an elastic continuum. The pie chart in figure 1 graphically depicts the two formulations. Cauchy developed the stress formulation in elasticity in 1822.

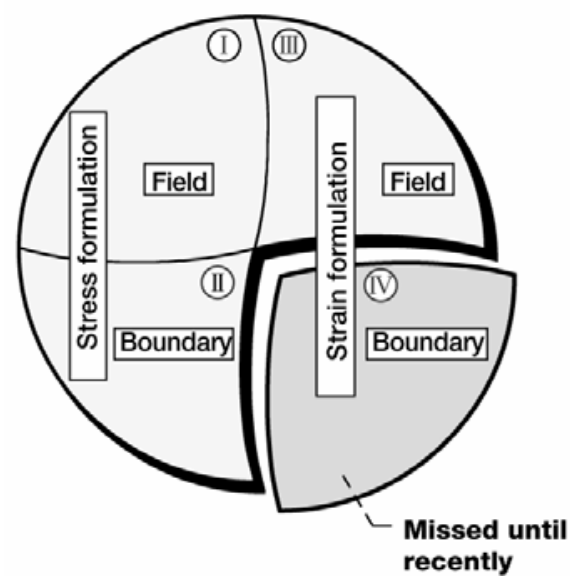

Figure 1.-Stress and strain formulations.

This contained two distinct sets of equations: the field equations $\tau_{i j, j}+b_{i}=0$, and boundary or traction conditions $p_{i}=\tau_{i j} n_{j}$. Here, $1 \leq i, j \leq 3, \tau_{i j}$ is the stress, and $b_{i}$ and $p_{i}$ are the body force and traction, respectively. The stress formulation occupies the left half of the pie chart. St. Venant provided the strain formulation in 1860, but only in the field of the continuum. It is depicted in the third quarter. The boundary portion - that was missed for over a century -is marked as the fourth quarter. It has been identified as the boundary compatibility condition (BCC). The BCC was formulated in the two-dimensional elasticity ${ }^{6}$ in 1986 and extended to three dimensions ${ }^{1}$ at the end of the twentieth century. A correct solution to an elasticity problem must satisfy all the equations contained in each of the four quarters of the pie diagram, even though a solution can be obtained by manipulating the information contained in the first three quarters of the chart. ${ }^{38}$ The fidelity of such a solution cannot be guaranteed. ${ }^{25}$

The boundary compatibility conditions, unlike the field counterpart, do not trivialize when expressed in terms of the displacement variables: neither on the boundary of an elastic continuum, nor along the numerous inter-element boundaries in a finite element model. If BCC are indeed independent conditions, and not redundant to the displacement continuity condition, then Navier's method becomes BCC noncompliant. This may pose a burden because a question can be raised as to the accuracy of the many existing solutions. ${ }^{39}$ Existing computer codes ${ }^{7,25}$ may have to be adjusted for the compliance of the BCC. Complacency, because the discipline is over a century old and computer codes have been in development for about half a century, can lead to its stagnation.

The importance of the compatibility condition (CC) cannot be overstated. Without the CC the solid mechanics discipline would degenerate into a few determinate analysis courses that could be covered in elementary strength of materials and applied mathematics. The compatibility concept makes solid mechanics a research discipline that is practiced at doctoral and post- 
doctoral levels in academia and in large research centers throughout the world. Traditional treatment of the compatibility concept in structures (i.e., 'cut' and close 'gap') and in elasticity (i.e., strain formulation) is inconsistent. In summary, the solid mechanics discipline has acknowledged the existence of CC. It has often been showcased. Used very sparingly. Confused with displacement continuity but has never been adequately researched nor understood.

Beltrami and Michell in 1900 attempted a direct stress calculation method, ${ }^{39}$ but it was not successful because of the nonavailability of the $\mathrm{BCC}^{\dagger}$. The BMF could not solve the more prevalent second and third boundary value problems with displacement and mixed boundary conditions. Navier's (1785-1836) formulation ${ }^{39}$ presumed to have resolved the impasse. He advocated calculating displacement first and then recovering stress by backsubstitution. The strain formulation available to Navier produced trivial conditions when expressed in displacement variables. This allowed Navier to bypass the strain formulation to develop the displacement method, which in essence contained the stress formulation, or information contained in the left half portion of the pie diagram. In finite element analysis, Navier's method became the stiffness method, which currently is the method of choice. Mathematically speaking Navier's method and the stiffness formulation are incomplete because they are compatibility noncompliant.

The new compatibility information contained in the fourth quarter of the pie chart has been used to formulate two direct stress calculation methods: Integrated Force Method (IFM) for finite element analysis and the completed Beltrami-Michell formulation (CBMF) in elasticity. CBMF is obtained by adding new BCC to the classical BMF. IFM is obtained by specializing the strain formulation for finite element models. Both IFM and CBMF bestow simultaneous emphasis on the stress and strain formulations. This paper outlines the basic compatibility concept. It is discussed through the solution of a plate flexure problem. Solution fidelity is shown in finite element analysis. The benefit in design optimization is presented. The cited references provide detailed discussion on the subject.

\section{Basic Compatibility Concept}

Coupling the stress formulation and the strain formulation yields a complete set of equations for the solution of stress in an elastic continuum. The concept can be stated by the following symbolic expression:

$$
\left[\begin{array}{l}
\text { Stress formulation } \\
- \text { Strain formulation }
\end{array}\right]\{\text { Stress }\}=\left\{\begin{array}{c}
\text { Mechanical load } \\
\text { Initial deformation }
\end{array}\right\}
$$

The expression bestows simultaneous emphasis on stress formulation (or equilibrium equation, EE) and strain formulation (or compatibility condition). It provides both necessary and sufficient conditions to calculate the stress tensor. Displacement can be back-calculated by integrating the stress. At this stage the rigid-body motion is eliminated. Displacement is not essential to calculate

\footnotetext{
${ }^{\dagger}$ "It is possible by taking account of these relations [the compatibility conditions] to obtain a complete system of equations which must be satisfied by stress components, and thus the way is open for a direct determination of stress without the intermediate steps of forming and solving differential equations to determine the components of displacements.”_Love ${ }^{39}$.
} 
the stress state. ${ }^{4}$ However, it has become the current medium of the solid mechanics discipline. Strain (or deformation) compliance is the central concept behind both the field and boundary compatibility conditions. The field compliance applies to the field. Compliance on the boundary becomes the BCC. The compatibility concept is illustrated considering a two-dimensional domain $D$ bounded by the simple curve $\Gamma$ shown in figure 2(a).

Field Compatibility: In the domain mark a field segment $F^{d}$ with the associated boundary $\Gamma^{d}$. This segment is segregated and depicted in figure 2(b) with domain $F^{s}$ and boundary $\Gamma^{s}$. Subject both segments, $\left(F^{d}\right.$ and $\left.\Gamma^{d}\right)$ and $\left(F^{s}\right.$ and $\left.\Gamma^{s}\right)$, to identical stress and strain states of the real problem. The field CC ensures that these segments fit without any gap or variation in material properties before and after deformation. St. Venant ${ }^{39}$ provided the mathematical equations for field compatibility in 1860 .

Boundary Compatibility: On the boundary curve, mark $C^{u}$ and $C^{d}$ for undeformed and deformed states, respectively, as shown in figure 2(a). The boundary segment is segregated and shown in figure 2(c) as $\left(C^{u s}\right.$ and $\left.C^{d s}\right)$. Both segments, $\left(C^{u}\right.$ and $\left.C^{d}\right)$ and $\left(C^{u s}\right.$ and $\left.C^{d s}\right)$, are subjected to identical stress and strain states of the actual problem. Like the field compliance, the boundary compatibility ensures that segments $\left(C^{u}\right.$ and $\left.C^{d}\right)$ and $\left(C^{u s}\right.$ and $\left.C^{d s}\right)$ fit without any gap or change in the material properties before and after deformation. The mathematical equation for BCC was formulated ${ }^{6}$ in 1986. In brief, the same basic compliance concept applies to the field or to the boundary, as the case may be.

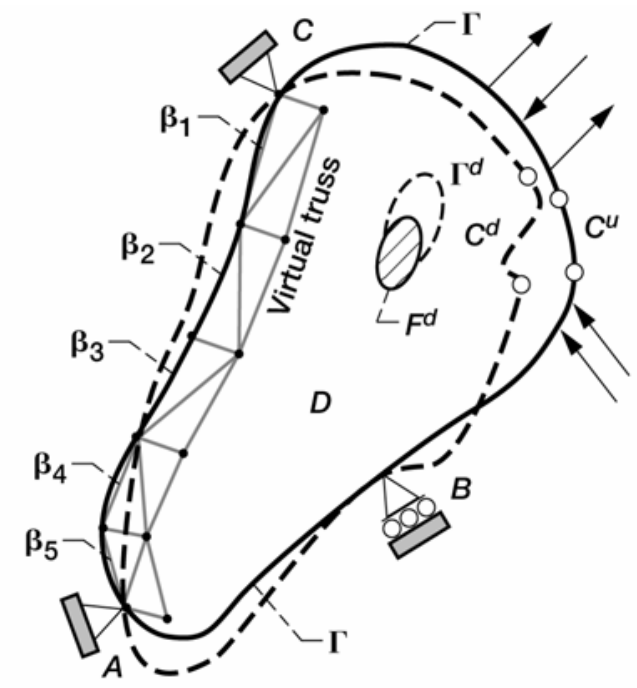

(a) Plane stress problem.

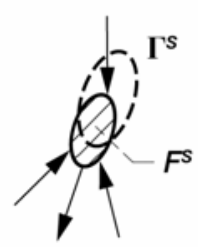

(b) Field segment.

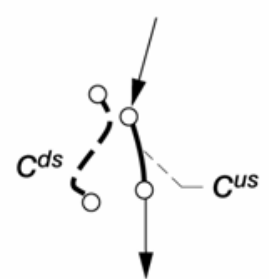

(c) Boundary segment.

\section{Undeformed configuration \\ - - Deformed configuration}

Figure 2.-Deformation compatibility in continuum. 
For an elastic continuum with a rigid boundary with no significant deformation, the BCC may exhibit automatic compliance, but this is most unlikely along the numerous interelement deformable boundaries in a finite element model. Consider next a discrete indeterminate truss with supports at A and C and its lower chord coinciding with the boundary segment. It is marked as a 'Virtual truss' in figure 2(a). The $i^{\text {th }}$ bar deformation is designated as $\beta_{i}$. The BCC for the truss is the balance of the elemental deformations along the boundary bars: $\left(\beta_{1}+\beta_{2}+\beta_{3}+\beta_{4}+\beta_{5}=0\right)$. The truss response will be erroneous if this BCC is not applied.

The compatibility is a controller type of relation. In elasticity the strains $\varepsilon$ are controlled, $f\left(\varepsilon_{x x}\right.$, $\left.\varepsilon_{y y}, \ldots, \varepsilon_{z x}\right)=0$, or the deformations $\beta$ are balanced, $f\left(\beta_{1}, \beta_{2}, \ldots, \beta_{n}\right)=0$, for a discrete structural system. The controller type of relations cannot be derived from an application of the standard concepts like "action equal to reaction" (leading to the EE), or the "cause effect relation" (that has given us Hooke's law), or the "continuity concept” used in finite element analysis. This is probably one important reason for the late development of these conditions. In elasticity, field compatibility can be derived by simply eliminating the three displacements from the six strain displacement relations. However, the derivation of the BCC required the use of variational calculus. ${ }^{6}$ For structures, however, a direct application of St. Venant's strain formulation would have sufficed. No calculus would have been required because, like EE, the CC is a set of algebraic equations. But such a procedure was not adopted, and the CC was not developed as a deformation balance concept.

In three-dimensional elasticity, ${ }^{1}$ the new BCC expressed in stress has the following form:

$$
\begin{aligned}
& \frac{\partial}{\partial z}\left\{a_{v z}\left(\sigma_{y}-v \sigma_{z}-v \sigma_{x}\right)-a_{v y}(1+v) \tau_{y z}\right\}+\frac{\partial}{\partial y}\left\{a_{v y}\left(\sigma_{z}-v \sigma_{x}-v \sigma_{y}\right)-a_{v z}(1+v) \tau_{y z}\right\}=0 \\
& \frac{\partial}{\partial x}\left\{a_{v x}\left(\sigma_{z}-v \sigma_{x}-v \sigma_{y}\right)-a_{v z}(1+v) \tau_{z x}\right\}+\frac{\partial}{\partial z}\left\{a_{v z}\left(\sigma_{x}-v \sigma_{y}-v \sigma_{z}\right)-a_{v x}(1+v) \tau_{z x}\right\}=0 \\
& \frac{\partial}{\partial y}\left\{a_{v y}\left(\sigma_{x}-v \sigma_{y}-v \sigma_{z}\right)-a_{v x}(1+v) \tau_{x y}\right\}+\frac{\partial}{\partial x}\left\{a_{v x}\left(\sigma_{y}-v \sigma_{z}-v \sigma_{x}\right)-a_{v y}(1+v) \tau_{x y}\right\}=0
\end{aligned}
$$

where, $v$ is Poisson's ratio, and $a_{\mathrm{vx}}, a_{v y}$, and $a_{\mathrm{vz}}$ are the direction cosines of the outward normal to the boundary surface.

The BCC written in terms of displacements ( $\mathrm{u}, \mathrm{v}$, and w), yield a nontrivial set of conditions.

$$
\begin{aligned}
& \Re_{1}=a_{v y} \frac{\partial^{2} v}{\partial z^{2}}+a_{v z} \frac{\partial^{2} w}{\partial y^{2}}-\frac{\partial^{2}}{\partial y \partial z}\left(a_{v z} v+a_{v y} w\right)=0 \\
& \Re_{2}=a_{v z} \frac{\partial^{2} w}{\partial x^{2}}+a_{v x} \frac{\partial^{2} u}{\partial z^{2}}-\frac{\partial^{2}}{\partial z \partial x}\left(a_{v x} w+a_{v z} u\right)=0
\end{aligned}
$$




$$
\mathfrak{R}_{3}=a_{v y} \frac{\partial^{2} v}{\partial x^{2}}+a_{v x} \frac{\partial^{2} u}{\partial y^{2}}-\frac{\partial^{2}}{\partial x \partial y}\left(a_{v y} u+a_{v x} v\right)=0
$$

The nontrivial BCC must be added to the displacement formulation because a correct solution must be BCC compliant. BCC in equation (3) are expressed in terms of the second derivatives of displacements. If such derivatives become zero at a boundary or at a finite element interface, then the BCC may be neglected. This is not likely at flexible boundaries. In other words the existing solutions should be verified and adjusted for BCC compliance, as will be presented in the following sections.

\section{Navier's Formulation with BCC}

The BCC has to be added to the Navier's formulation as shown in the following equations:

(1) The three field equations are not changed.

$$
\begin{aligned}
& (\lambda+G) \frac{\partial \varepsilon}{\partial x}+G \nabla^{2} u+F_{x}=0 \\
& (\lambda+G) \frac{\partial \varepsilon}{\partial y}+G \nabla^{2} v+F_{y}=0 \\
& (\lambda+G) \frac{\partial \varepsilon}{\partial z}+G \nabla^{2} \omega+F_{z}=0
\end{aligned}
$$

where, $\lambda$ and $G$ are Lamé constants, and $\varepsilon=\frac{\partial u}{\partial x}+\frac{\partial v}{\partial y}+\frac{\partial w}{\partial z}$.

(2) The stress or traction boundary conditions also are not changed.

$$
\begin{aligned}
& T_{x}^{\mu}=\lambda \varepsilon a_{v x}+G\left(\frac{\partial u}{\partial x} a_{v x}+\frac{\partial u}{\partial y} a_{v y}+\frac{\partial u}{\partial z} a_{v z}\right)+G\left(\frac{\partial u}{\partial x} a_{v x}+\frac{\partial v}{\partial x} a_{v y}+\frac{\partial w}{\partial x} a_{v z}\right) \\
& T_{y}^{\mu}=\lambda \varepsilon a_{v y}+G\left(\frac{\partial v}{\partial y} a_{v y}+\frac{\partial v}{\partial z} a_{v z}+\frac{\partial v}{\partial x} a_{v x}\right)+G\left(\frac{\partial v}{\partial y} a_{v y}+\frac{\partial w}{\partial y} a_{v z}+\frac{\partial u}{\partial y} a_{v x}\right) \\
& T_{z}^{\mu}=\lambda \varepsilon a_{v z}+G\left(\frac{\partial w}{\partial z} a_{v z}+\frac{\partial w}{\partial x} a_{v x}+\frac{\partial w}{\partial y} a_{v y}\right)+G\left(\frac{\partial w}{\partial z} a_{v z}+\frac{\partial u}{\partial z} a_{v x}+\frac{\partial v}{\partial z} a_{v y}\right)
\end{aligned}
$$


(3) Boundary compatibility conditions must be added to the classical formulation:

$$
\begin{array}{ll}
a_{v y} \frac{\partial^{2} v}{\partial z^{2}}+a_{v z} \frac{\partial^{2} w}{\partial y^{2}}-\frac{\partial^{2}}{\partial y \partial z} & \left(a_{v z} v+a_{v y} w\right)=0 \\
a_{v z} \frac{\partial^{2} w}{\partial x^{2}}+a_{v x} \frac{\partial^{2} u}{\partial z^{2}}-\frac{\partial^{2}}{\partial z \partial x} & \left(a_{v x} w+a_{v z} u\right)=0 \\
a_{v y} \frac{\partial^{2} v}{\partial x^{2}}+a_{v x} \frac{\partial^{2} u}{\partial y^{2}}-\frac{\partial^{2}}{\partial x \partial y} & \left(a_{v y} u+a_{v x} v\right)=0
\end{array}
$$

(4) Displacement boundary conditions: The kinematics conditions are essential.

$$
u=\bar{u}, \quad v=\bar{v}, \quad \text { and } \quad w=\bar{w}
$$

Navier's formulation is incomplete because BCC given by equation (6) was missed.

\section{Completed Beltrami-Michell Formulation}

CBMF considers stress as the primary unknown. It has been derived from the stationary condition of the IFM functional. ${ }^{1}$ The basic equations of CBMF are reproduced:

Field equilibrium equations:

$$
\begin{gathered}
\frac{\partial \sigma_{x}}{\partial x}+\frac{\partial \tau_{x y}}{\partial y}+\frac{\partial \tau_{z x}}{\partial z}+B_{x}=0 \\
\frac{\partial \tau_{x y}}{\partial x}+\frac{\partial \sigma_{y}}{\partial y}+\frac{\partial \tau_{y z}}{\partial z}+B_{y}=0 \\
\frac{\partial \tau_{z x}}{\partial x}+\frac{\partial \tau_{y z}}{\partial y}+\frac{\partial \sigma_{z}}{\partial z}+B_{z}=0
\end{gathered}
$$

Field compatibility conditions:

$$
\frac{\partial^{2}}{\partial z^{2}}\left(\sigma_{y}-v \sigma_{z}-v \sigma_{x}\right)+\frac{\partial^{2}}{\partial y^{2}}\left(\sigma_{z}-v \sigma_{x}-v \sigma_{y}\right)-2(1+v) \frac{\partial^{2} \tau_{y z}}{\partial y \partial z}=0
$$




$$
\begin{aligned}
& \frac{\partial^{2}}{\partial x^{2}}\left(\sigma_{z}-v \sigma_{x}-v \sigma_{y}\right)+\frac{\partial^{2}}{\partial z^{2}}\left(\sigma_{x}-v \sigma_{y}-v \sigma_{z}\right)-2(1+v) \frac{\partial^{2} \tau_{z x}}{\partial z \partial x}=0 \\
& \frac{\partial^{2}}{\partial y^{2}}\left(\sigma_{x}-v \sigma_{y}-v \sigma_{z}\right)+\frac{\partial^{2}}{\partial x^{2}}\left(\sigma_{y}-v \sigma_{z}-v \sigma_{x}\right)-2(1+v) \frac{\partial^{2} \tau_{x y}}{\partial x \partial y}=0
\end{aligned}
$$

(3) Boundary equilibrium or traction conditions:

$$
\begin{aligned}
& a_{v x} \sigma_{x}+a_{v y} \tau_{x y}+a_{v z} \tau_{x z}=\bar{P}_{x} \\
& a_{v x} \tau_{x y}+a_{v y} \sigma_{y}+a_{v z} \tau_{y z}=\bar{P}_{y} \\
& a_{v x} \tau_{x z}+a_{v y} \tau_{y z}+a_{v z} \sigma_{z}=\bar{P}_{z}
\end{aligned}
$$

(4) Boundary compatibility conditions:

$$
\begin{aligned}
& \frac{\partial}{\partial z}\left\{a_{v z}\left(\sigma_{y}-v \sigma_{z}-v \sigma_{x}\right)-a_{v y}(1+v) \tau_{y z}\right\}+\frac{\partial}{\partial y}\left\{a_{v y}\left(\sigma_{z}-v \sigma_{x}-v \sigma_{y}\right)-a_{v z}(1+v) \tau_{y z}\right\}=0 \\
& \frac{\partial}{\partial x}\left\{a_{v x}\left(\sigma_{z}-v \sigma_{x}-v \sigma_{y}\right)-a_{v z}(1+v) \tau_{z x}\right\}+\frac{\partial}{\partial z}\left\{a_{v z}\left(\sigma_{x}-v \sigma_{y}-v \sigma_{z}\right)-a_{v x}(1+v) \tau_{z x}\right\}=0 \\
& \frac{\partial}{\partial y}\left\{a_{v y}\left(\sigma_{x}-v \sigma_{y}-v \sigma_{z}\right)-a_{v x}(1+v) \tau_{x y}\right\}+\frac{\partial}{\partial x}\left\{a_{v x}\left(\sigma_{y}-v \sigma_{z}-v \sigma_{x}\right)-a_{v y}(1+v) \tau_{x y}\right\}=0
\end{aligned}
$$

The three BCC given by equation (11) had been missing since 1860 .

(5) Displacement continuity conditions:

$$
u=\bar{u}, \quad v=\bar{v}, \quad \text { and } \quad w=\bar{w}
$$

CBMF is defined through the EE and the CC in the field and on the boundary of an elastic continuum, given by equations (8) to (11). Stress determination by CBMF does not require the displacement boundary conditions. The displacement functions, $u(x, y, z), v(x, y, z)$, and $w(x, y$, $z$ ), if required, can be determined by integrating the known stress. The calculation of the constants of integration in the displacement functions requires the displacement boundary conditions given by equation (12). CBMF can be used for analysis of stress, displacement, and mixed boundary value problems. A correct solution must satisfy all elasticity equations (eqs. (8) to (12)) in CBMF or its equivalent (eqs. (4) to (7)) in the displacement method. Solutions that have been obtained without the use of the BCC should be verified for the compliance, especially for a continuum with deformable boundaries. In traditional solutions to the elasticity problem, 
displacement continuity conditions are augmented with the slope or derivative of displacement. For some problems the "slope" condition may resemble the boundary compatibility condition.

\section{Solution of a Plate Flexure Problem}

The use of BCC is illustrated considering a flat plate in flexure ${ }^{3}$, as shown in figure 3 . It has clamped boundaries along edges $\mathrm{AB}$ and DC. The edges AD and BC are simply supported. It has spans $2 a$ and $2 c$ and thickness $h$. It is made of an isotropic material with modulus $E$ and Poisson's ratio $v$. It is subjected to a sinusoidal distributed load $q=q_{0} \cos \alpha x, \alpha=\pi / 2$ a. It has three moment variables $M_{x}, M_{y}$, and $M_{x y}$, and one transverse displacement $w$. The problem is to determine the moment and the displacement functions.

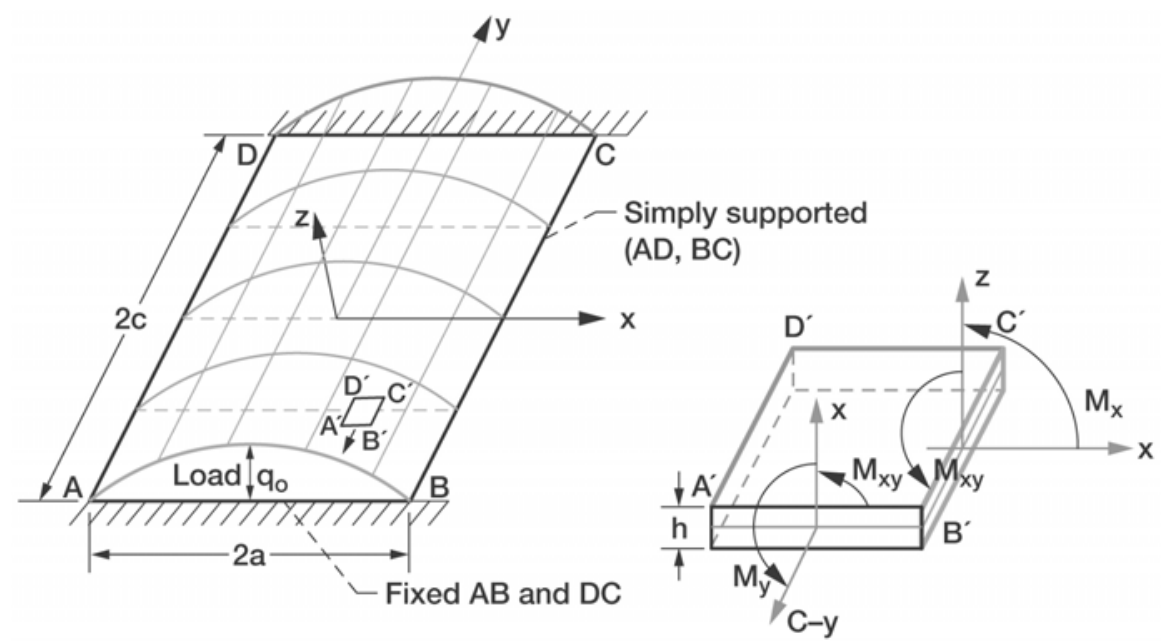

Figure 3.--Rectangular plate in flexure.

Displacement method solution: Traditionally the problem is solved using the stiffness method. The transverse displacement $w$ is considered as the primary unknown. It is obtained by solving a fourth-order differential equation, $\nabla^{4} w=q / D$, where $D=\frac{E h^{3}}{12\left(1-v^{2}\right)}$ is the plate rigidity and $q$ is the transverse load. At simple supports $\frac{\partial^{2} w}{\partial x^{2}}+v \frac{\partial^{2} w}{\partial y^{2}}=0$ and $w=0$; for clamped boundary conditions $w=0$ and $\frac{\partial w}{\partial y}=0$. The moment functions are back calculated from the displacement. The available textbook solution ${ }^{39}$ is not reproduced here.

Force Method Solution: CBMF considers three moments $M_{x}, M_{y}$ and $M_{x y}$ as the primary unknowns. The CBMF is derived from the stationary condition of the IFM variational functional. ${ }^{6}$ The three original CBMF equations are reduced to two by eliminating the $M_{x y}$ moment function using the following two field compatibility conditions: 


$$
\begin{aligned}
& \frac{\partial}{\partial x}\left(M_{y}-v M_{x}\right)-(1+v) \frac{\partial}{\partial y} M_{x y}=0 \\
& \frac{\partial}{\partial y}\left(M_{x}-v M_{y}\right)-(1+v) \frac{\partial}{\partial x} M_{x y}=0
\end{aligned}
$$

The equations required for a rectangular plate with straight boundaries are listed in table 1 . The conditions on straight boundaries parallel to the coordinate axes are quite simple because one component of the direction cosine is zero, while the other is unity. In the field there are two second-order differential equations that can be solved one after the other, but not simultaneously.

TABLE 1.-COMPLETED BELTRAMI-MICHELL FORMULATION FOR PLATE FLEXURE PROBLEM

\begin{tabular}{ll}
\hline \hline \multicolumn{1}{c}{ Field equations } & \multicolumn{1}{c}{ Boundary conditions } \\
\hline$\nabla^{2}\left(M_{x}+M_{y}\right)=(1+v) q$ & Along simply supported edges (BC, AD) \\
& $M_{x}=0, M_{y}=0$ \\
$\frac{\partial^{2}}{\partial x^{2}}\left(M_{y}-v M_{x}\right)+\frac{\partial^{2}}{\partial y^{2}}\left(v M_{y}-M_{x}\right)=0$ & Along clamped edges (AB, CD) \\
& $\left(M_{x}-v M_{y}\right)=0, M_{x y}=0$ \\
& Rigid boundary conditions along all edges \\
& $w=0$ \\
\hline \hline
\end{tabular}

The boundary conditions of the force and displacement methods are compared in table 2. Both methods impose the rigid body condition on transverse displacement $w$ which does not produce any moment. This condition is not used in CBMF during the calculation of moments. In CBMF the moment boundary conditions, when written in displacement, give rise to conditions on curvatures. On simply supported boundary both curvatures are restrained. In clamped boundary the normal and shear curvatures are set to zero. In the stiffness method, boundary conditions are imposed on displacement and slope but not in terms of curvature. It is important to note that the CBMF conditions when expressed in the displacement variable, do not automatically map into the boundary conditions of the stiffness method, (compare third and fourth columns in Table 2). For this problem the boundary conditions can be shown to be equivalent. Consider the clamped boundary AB. The slope condition $\left(\frac{\partial w}{\partial y}=0\right.$, for $\left.(-\mathrm{a} \leq \mathrm{x} \leq \mathrm{a})\right)$, when differentiated with respect to the $\mathrm{X}$-coordinate, transforms to the CBMF condition on curvature: $\left(\frac{\partial^{2} w}{\partial x \partial y}=0\right)$. Likewise the displacement condition ( $w=0$, for $(-\mathrm{a} \leq \mathrm{x} \leq \mathrm{a})$ ) becomes the curvature $\left(\frac{\partial^{2} w}{\partial^{2} x}=0\right)$ for CBMF. Such a transformation becomes invalid if the rigid (or uniformity) condition is not allowed, such as for example along a flexible finite element interface. All boundary conditions, including the continuity conditions in the finite element analysis, must be examined for equivalence between the force and displacement methods. 
TABLE 2.-BOUNDARY CONDITIONS

\begin{tabular}{cccc}
\hline \hline \multirow{2}{*}{ Boundary Type } & \multicolumn{2}{c}{ Completed Beltrami Michell's Formulation } & $\begin{array}{c}\text { Stiffness Method } \\
\text { In displacement }\end{array}$ \\
\cline { 2 - 3 } Simple Support & In moment variable & In curvature & $\frac{\partial^{2} w}{\partial x^{2}}+v \frac{\partial^{2} w}{\partial y^{2}}=0$ \\
$M_{y}=0$ & $\frac{\partial^{2} w}{\partial x^{2}}=0$ & $\frac{\partial^{2} w}{\partial y^{2}}=0$ & \\
Clamped & $M_{x}-v M_{y}=0$ & $\frac{\partial^{2} w}{\partial x^{2}}=0$ & $\frac{\partial w}{\partial y}=0$ \\
Rigid Condition & $M_{x y}=0$ & $\frac{\partial^{2} w}{\partial x \partial y}=0$ & \\
\hline \hline
\end{tabular}

Boundary conditions specified directly on moments (or forces) are used in the CBMF and also in BMF. The classical method cannot handle the displacement and slope boundary conditions. In other words the plate problem cannot be solved by the classical BMF because the transformation of displacement $w=0$ and slope conditions $\frac{\partial w}{\partial x}=0$ into moments is difficult, and it may require integral equations. Consequently the classical method became inapplicable for solution of the vast problems with displacement conditions. Thus Navier's displacement formulation is used for continuum analysis. The Navier method again is incomplete with respect to the BCC, see equation (6). The BCC obtained from the stationary condition of the variational functional of IFM $^{6}$ has produced the required boundary conditions, in moment (force) variables, see equations in table 2. The displacement condition $w=0$ along the four edges of the plate is not used to calculate the moment functions in CBMF because this is a rigid-body motion and does not induce any stress in the plate. The rigid boundary conditions are used to back calculate the displacement function $w$ from the moments.

\section{Solution Strategy}

In the CBMF a second-order differential equation (see Table 1) is solved first to obtain $M_{x}+M_{y}$. Then the second equation is transformed and solved independently. CBMF requires the solution of two second-order uncoupled differential equations. It is simpler than the stiffness method which must solve a fourth-order differential equation. The CBMF solution is obtained using separation of variables.

$$
\begin{aligned}
& M_{x}=\overline{M_{x}}(y) \cos \alpha x \\
& M_{y}=\overline{M_{y}}(y) \cos \alpha x
\end{aligned}
$$




$$
M_{x y}=\overline{M_{x y}}(y) \sin \alpha x
$$

The CBMF moment $\left(M_{x}, M_{y}\right.$, and $\left.M_{x y}\right)$ solution follows:

$$
\begin{gathered}
M_{x}=\cos \alpha x\left[C_{3}\left(e^{\alpha y}+e^{-\alpha y}\right)-\alpha \frac{(1-v)}{2(1+v)} C_{1} y\left(e^{\alpha y}-e^{-\alpha y}\right)-\frac{q_{0}}{\alpha^{2}}\right] \\
M_{y}=\cos \alpha x\left[\left(C_{1}-C_{3}\right)\left(e^{\alpha y}+e^{-\alpha y}\right)+\alpha \frac{(1-v)}{2(1+v)} C_{1} y\left(e^{\alpha y}-e^{-\alpha y}\right)-v \frac{q_{0}}{\alpha^{2}}\right] \\
M_{x y}=\frac{\sin \alpha x}{2}\left[\left(2 C_{3}-C_{1}\right)\left(e^{\alpha y}-e^{-\alpha y}\right)-\alpha \frac{(1-v)}{(1+v)} C_{1} y\left(e^{\alpha y}+e^{-\alpha y}\right)\right]
\end{gathered}
$$

The displacement calculation uses the rigid-body boundary condition $w=0$. In other words CBMF uses conditions on moments (or curvatures) to calculate moments. The displacement $w$ boundary condition is used to calculate the displacement function. The slope condition of a clamped boundary was not used explicitly. This is automatically satisfied through the BCC. The displacement function has the following form:

$$
w=\frac{-\cos \alpha x}{\alpha^{2} D\left(1-v^{2}\right)}\left[C_{3}(1+v)\left(e^{\alpha y}+e^{-\alpha y}\right)-v C_{1}\left(e^{\alpha y}+e^{-\alpha y}\right)-\alpha \frac{(1-v)}{2} C_{1} y\left(e^{\alpha y}+e^{-\alpha y}\right)-\frac{q_{0}}{\alpha^{2}}\left(1-v^{2}\right)\right]
$$

The constants $C_{1}$ and $C_{3}$ are as follows:

$$
\begin{gathered}
C_{1}=\left(2 \frac{q_{0}}{\alpha^{2}}\right)(1+v) \frac{e^{\alpha c}-e^{-\alpha c}}{e^{2 \alpha c}+4 \alpha c-e^{-2 \alpha c}} \\
C_{3}=\frac{q_{0}}{\alpha^{2}} \frac{(1+v)\left(e^{\alpha c}-e^{-\alpha c}\right)+\alpha(1-v) c\left(e^{\alpha c}+e^{-\alpha c}\right)}{e^{2 \alpha c}+4 \alpha c-e^{-2 \alpha c}}
\end{gathered}
$$

An identical solution is obtained by the stiffness method because the boundary conditions become equivalent between the force and the displacement methods.

\section{Finite Element Discrete Analysis}

Strain formulation in discrete analysis (that included framework and a finite element model) was neither fully understood in the field nor on the boundary, even though its requirement was known. The technique of "cut" and close "gap" in structures ${ }^{20}$ is quite different than the strain formulation in elasticity. An understanding of the compatibility conditions for discrete systems $^{18,19,21}$ has lead to the formulation of the Integrated Force Method. IFM with internal 
force $\{F\}$ as the unknown is the discrete analog of the CBMF in elasticity. IFM constrains the solution to satisfy both the stress and strain formulations simultaneously, and this promotes solution fidelity. A dual formulation to the primal IFM (IFMD) with displacement as the primary unknown has been obtained by mapping force into displacement $\{X\}$. Its governing equation resembles the stiffness equation $[K]\{X\}=\{P\}$. The equations of the IFM and IFMD, along with the mixed and hybrid methods for static and frequency analysis, are listed next.

Integrated Force Method:

Static analysis:

$$
\begin{gathered}
{[S]\{F\}=\{P\}} \\
\{X\}=[J]\left\{[G]\{F\}+\left\{\beta^{0}\right\}\right\} \\
{[S]=\left[\frac{[B]}{[C][G]}\right]} \\
{[J]=m \text { rows of }\left([S]^{-1}\right)^{T}}
\end{gathered}
$$

Dynamic analysis:

$$
\left(S-\omega^{2}\left[\frac{[M J G]}{[0]}\right]\right)\{F\}=0
$$

Dual Integrated Force Method:

Static analysis:

$$
\begin{gathered}
{[D]\{X\}=\{P\}} \\
{[D]=[B][G]^{-1}[B]^{T}} \\
\{F\}=[G]^{-1}[B]^{T}\{X\}-[G]^{-1}\{\beta\}^{0}
\end{gathered}
$$

Dynamic analysis:

$$
\left(D-\omega^{2} M\right) \vec{X}=0
$$


Stiffness method: The governing equation is

$$
[K]\{X\}=\{P\}
$$

Mixed method: The governing equation is

$$
\left[\begin{array}{cc}
S & 0 \\
-J G & I
\end{array}\right]\left\{\begin{array}{l}
F \\
X
\end{array}\right\}=\left\{\begin{array}{l}
P \\
0
\end{array}\right\}
$$

Total formulation: The governing equation is

$$
\left[\begin{array}{ccc}
S & 0 & 0 \\
-J G & I & 0 \\
-G & 0 & I
\end{array}\right]\left\{\begin{array}{l}
F \\
X \\
\beta
\end{array}\right\}=\left\{\begin{array}{l}
P \\
0 \\
0
\end{array}\right\}
$$

where

$\{F\} \quad \mathrm{n}$ component internal force vector.

$\{P\} \quad m$ component external load vector.

$\{\delta R\} \quad(r=n-m)$ component effective initial deformation vector.

$\left\{\beta^{\circ}\right\} \quad n$ component initial deformation vector.

$\{\beta\} \quad n$ component deformation vector.

$\{X\} \quad m$ component displacement vector.

[S] $\quad(n \times n)$ IFM governing matrix.

[B] $\quad(m \times n)$ equilibrium matrix.

[G] $\quad(n \times n)$ flexibility matrix.

$[J] \quad(m \times n)$ displacement coefficient matrix.

[M] $\quad(m \times m)$ mass matrix.

[D] $\quad(m \times m)$ IFMD governing matrix.

$[K] \quad(m \times m)$ stiffness matrix.

$m \quad$ number of displacement unknowns.

$n \quad$ number of force unknowns.

$\omega \quad$ circular frequency.

Both IFM and IFMD have one equation to calculate force $\{F\}$, and another to calculate displacement $\{X\}$. The stiffness method has a single equation to calculate displacement. Stress is recovered through a series of back calculations. Stress recovery by differentiating approximate displacement can be a viable source of error. The equations of the stiffness method, the mixed method, and the total formulation have been derived from IFM as special cases. The reverse course, i.e. the stiffness equation cannot be specialized to obtain IFM, as depicted in figure 4 . With a small programming effort, a stiffness method code can be improved to reap the many IFM benefits when implemented with the IFMD elements because IFM and IFMD yield identical solutions. $^{25}$ 


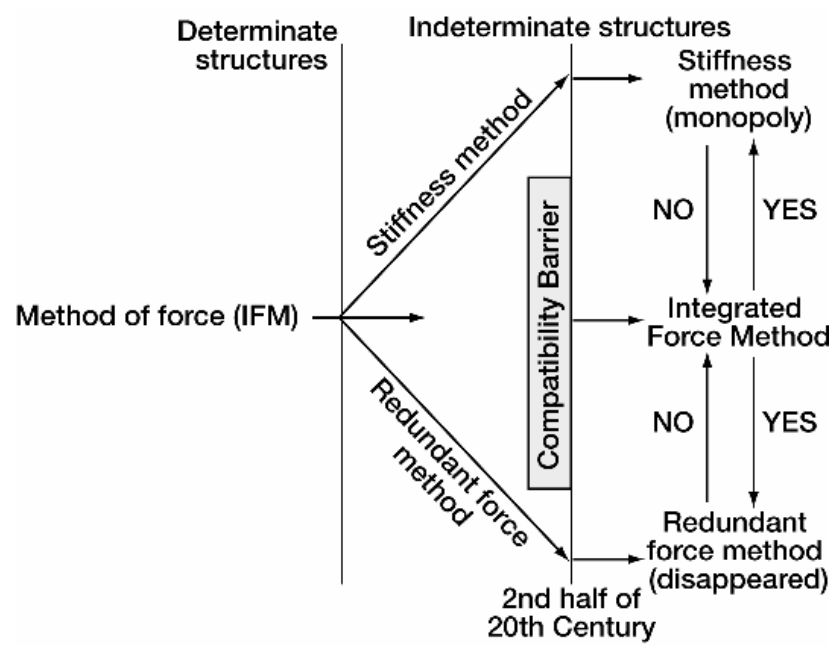

Figure 4.-Compatibility barrier prevented extension of force method for indeterminate structures.

The compatibility limitation blocked the growth of the method of forces, as sketched in figure 4. It caused a bifurcation of the analysis method into the stiffness method and the redundant-force method. Limitations of the redundant force method led to its demise. ${ }^{20}$ The monopolistic dominance of the stiffness method is not justified because of compatibility noncompliance along numerous inter-element boundaries in a finite element model. IFM retains both equilibrium and compatibility concepts. IFM has been specialized to obtain the stiffness method (see eq. 21), mixed method eq. 22, and the total formulation eq. 23.

$\underline{\text { IFM/Analyzers Code }}{ }^{11}$ : The finite element code incorporates IFM and IFMD, as well as the stiffness method. The Fortran 77 code is written for both sequential and parallel calculations. It performs linear analysis for mechanical and thermal loads, and initial displacement, as well as frequency analysis. The code has a total of 44 different types of elements for each method. Its element library includes beam, membrane, plate, and solid elements of different shapes. Some elements have mid-side nodes. The analyzer uses the NASA GPS sparse solver and Harwell routines. Solutions have been obtained for finite element models up to one-half million unknowns. The IFM/Analyzer has also been reduced to obtain a modest code with all three methods. The small code entitled IFM-UE can be used for undergraduate education in engineering. It is available at the IFM Website for Undergraduate Education. ${ }^{7}$ The solution capacity of this code is about 5000 equations. It has five different types of elements that can model skeletal frames and membrane structures.

Solution fidelity: IFM, IFMD, and stiffness method have been compared in a controlled environment for a set of test problems. ${ }^{11,16,17}$ Results for a few typical examples obtained using the IFM/Analyzers code and a commercial stiffness method code are depicted in figure 5 . The three IFM elements used are (1) a four-node QUAD0405 membrane element with five force unknowns, (2) an eight-node brick element HEX0818 with 18 force unknowns, and (3) a fournode-plate bending element PLB0409 with nine unknown moments. These elements use standard displacement functions. Element generation used numerical integration but did not use reduced integration or bubble function techniques. 


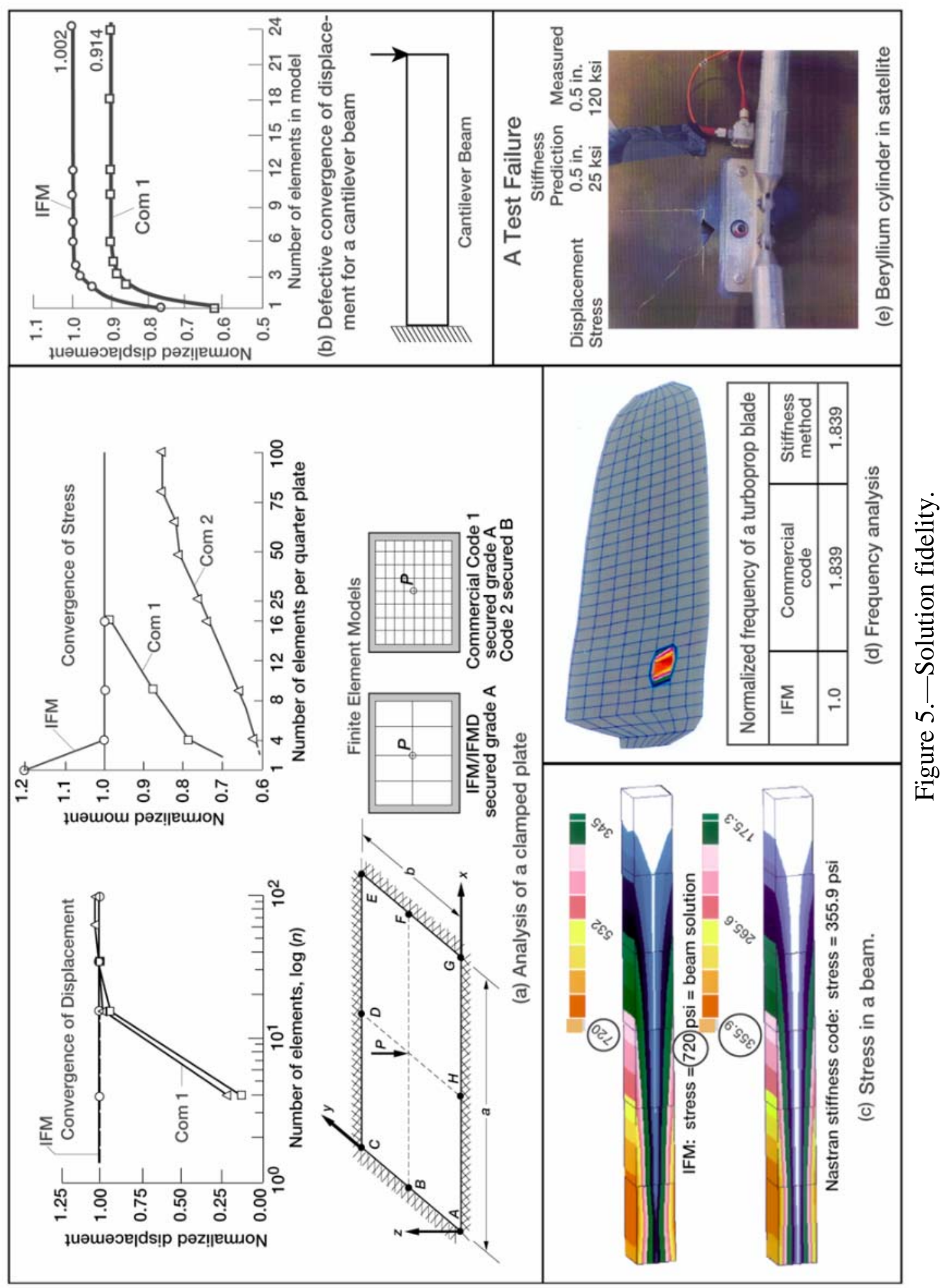


Displacement and moment solutions for a flat plate under a concentrated load are given in figure 5(a). Convergence is achieved for IFM with eight elements. The stiffness method based commercial code required 64 elements. The displacement solution for a cantilever beam using membrane elements is shown in figure 5(b). The stress solution using a hexahedral element is depicted in figure 5(c). For IFM both stress and displacement converged for a model with six elements. The commercial code converged to a wrong solution. The frequency analysis of a turboprop blade using brick element is given in figure 5(d). The stiffness method prediction for the fundamental frequency was 80 percent erroneous. Stress concentration in the blade due to a small hole is qualitatively shown as an 'eye'. The test results and stiffness method predictions for a beryllium cylinder in a satellite structure are shown in figure 5(e). The measured displacement of $0.5 \mathrm{in}$. matched with the prediction, but the measured stress of $120 \mathrm{ksi}$ was well below the calculated stress of 25 ksi. From this study, which also included commercial software packages, it was observed that IFM and/or IFMD produced accurate stress, displacement, and frequency results even for modest finite element models. The stiffness method quite often lacked precision. For the examples the integrated force method outperformed the stiffness method, overshadowing the simplicity at its element level.

The developer of the commercial code disputed the IFM results. ${ }^{25}$ To address this concern we solved all the examples again. The versions of the MSC/Nastran code used were: 70.7.0 Silicon graphics/IRIX64 6.5 (2001), 69.0 IBM/RISC System/6000 (1997), and MSC/Nastran (1982). No numerical inaccuracy was detected in any of the seven tables in the paper. ${ }^{11}$ For illustration we have selected the simple cantilever problem. It was solved using IFM and the MSC/Nastran code. Results obtained are given in table 3 and graphed in figure 6 . The earlier version of the MSC/Nastran code exhibited a residual error of 8.6 percent in the solution (see fig. 5(b)). But the solution from the current version of the MSC/Nastran code (which must have implemented the IFMD element ${ }^{25}$ ) is identical to IFMD results (see fig. 6). The tip displacement and the diagonal terms of the governing matrix for IFMD, two versions of MSC/Nastran code, and the standard stiffness method for a two-element model are given in table 3. The current version of MSC/Nastran code has now produced the coefficients that are identical to the IFMD, even though the earlier version of the MSC/Nastran code exhibited error. For the example, neither monotonic convergence (see figs. 6 and 5(b)) nor a big finite element model could guarantee high fidelity solution in the stiffness method. Solution accuracy should be estimated from the residue of equilibrium equations and compatibility conditions.

TABLE 3.-SOLUTION FOR A TWO-ELEMENT MODEL

\begin{tabular}{|c|c|c|}
\hline & $\begin{array}{l}\text { Tip displacement } \\
\text { in } 10^{-3} \text { in. }\end{array}$ & Diagonal coefficients of governing matrix \\
\hline IFM/IFMD & -1.1008 & ${ }^{\mathrm{a}}\left[\begin{array}{llllllll}6.1 & 16.6 & 3.0 & 8.3 & 3.0 & 8.3 & 6.1 & 16.6\end{array}\right]$ \\
\hline Timoshenko’s solution & -1.152 & \\
\hline Stiffness method & -0.2576 & b[ $\left[\begin{array}{llllllll}1.25 & 1.03 & 1.27 & 1.04 & 1.27 & 1.04 & 1.25 & 1.03\end{array}\right]$ \\
\hline MSC/Nastran, 1990 & -1.0055 & ${ }^{b}\left[\begin{array}{lllllllll}1.0 & 1.02 & 1.0 & 1.01 & 1.0 & 1.01 & 1.0 & 1.02\end{array}\right]$ \\
\hline $\begin{array}{l}\text { MSC/Nastran, } 2001 \\
\text { (Identical to IFM/IFMD) }\end{array}$ & -1.1008 & $\mathrm{~b}^{\mathrm{b}}\left[\begin{array}{llllllll}1.0 & 1.0 & 1.0 & 1.0 & 1.0 & 1.0 & 1.0 & 1.0\end{array}\right]$ \\
\hline
\end{tabular}




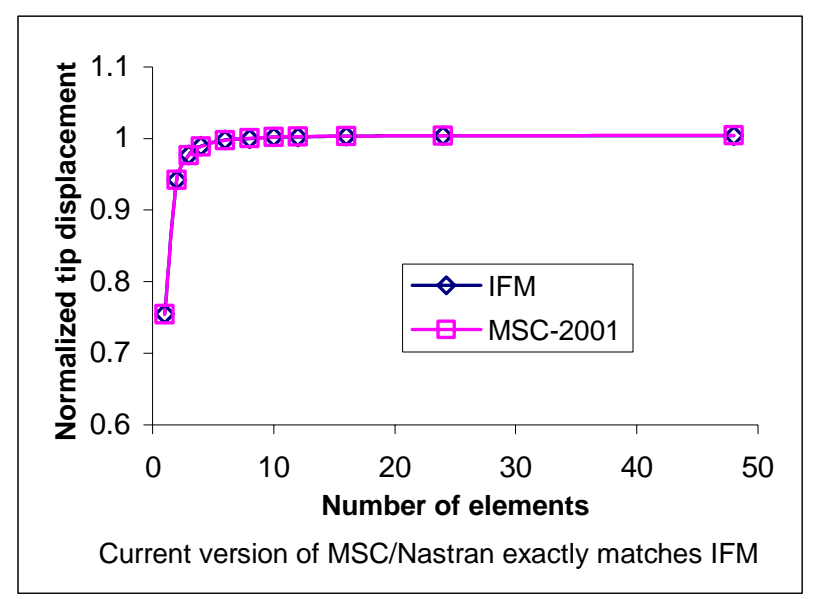

Figure 6.—Solution for a cantilever beam.

\section{Design Optimization}

The compatibility conditions must be accounted for in the design of indeterminate structures. An understanding and utilization of CC can produce efficient and safe structures. IFM is the preferred analysis tool in design because of the following four unique features:

(1) Flexibility matrix: The sizing design parameters are retained in a pristine state in the flexibility matrix $[G]$. This matrix only has to be updated during the design iterations.

(2) The EE matrix $[B]$ and the CC matrix $[C]$ are independent of sizing design variables. The EE matrix $[B]$ in the IFM equation is confined to an individual element. For example, EE matrices of element $i$ and element $j$ are not intermingled. In contrast, the inverse of the flexibility matrix, intermingled with the equilibrium matrix, is scattered through out the governing matrix $[K]$ in the stiffness method. This facilitates the calculation of the shape design parameters via IFM.

(3) Closed-form design sensitivity for stress, displacement, and frequency constraints required for optimization are easily obtained via $\operatorname{IFM}^{32}$ because matrices $[B]$ and $[C]$ are independent of the design parameters, and the flexibility matrix is a concatenation of elemental matrices.

(4) Direct-design and fully utilized design methods have been formulated through IFM. ${ }^{27}$ This is possible because the force variables can easily be linked to the design parameters.

The benefits that accrue from IFM in design have been demonstrated for trusses. ${ }^{31,33,34}$ The influence of compatibility in design is discussed for three issues.

\section{1) Infeasibility of fully stressed design}

The compatibility conditions make a fully stressed design infeasible for an indeterminate truss. Consider for example the five-bar truss shown in figure 7(a). Its compatibility condition expressed in terms of member stress $\sigma_{i}$ is $\sigma_{1}+1.01 \sigma_{2}-1.05 \sigma_{3}-1.02 \sigma_{4}+0.04 \sigma_{5}=0$. It is independent of member areas. The truss cannot be fully stressed $\sigma_{i}=\sigma_{0}, i=1,2, \ldots, 5$ to material strength $\sigma_{0}$ when member areas are considered as variables. The infeasibility of the full-stress design was derived in 1969. ${ }^{34}$ It has since been extended for stress and displacement constraints. ${ }^{31}$ The design can converge to a truss that is either determinate or close to it when the 
CCs are disregarded. Such a design may not be attractive to the industry because of safety and over-design considerations.

\section{2) Singularity in optimization ${ }^{29}$}

Design optimization can encounter singularity because the compatibility condition imposes functional dependency among the active stress constraints, as well as the stress and displacement constraints. The design direction can become unreliable because of the singularity of the coefficient matrix of the search direction. The singularity issue is illustrated considering the design optimization of the five-bar truss shown in figure 7(a), for minimum weight condition for stress and displacement constraints. A quadratic programming algorithm was used to solve the problem. The design iterations are shown in figures 7(b) and (c) for two cases:

(1) Singularity is disregarded (see figure 7(b)).

(2) It is alleviated through the compatibility formulation (see figure 7(c)).

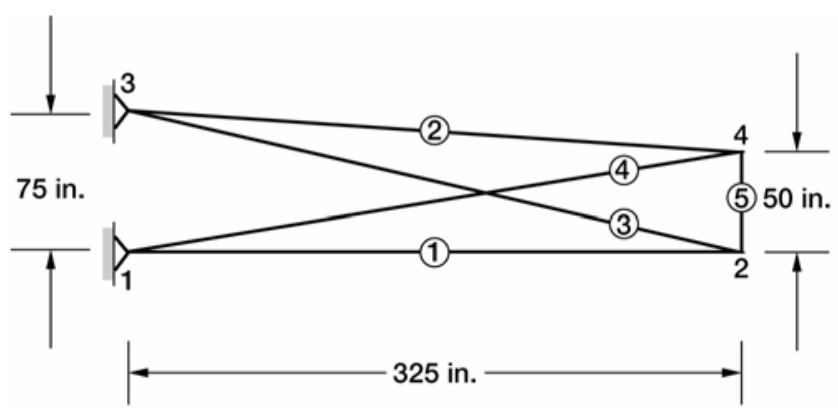

Figure 7(a).--Tapered one-bay truss.

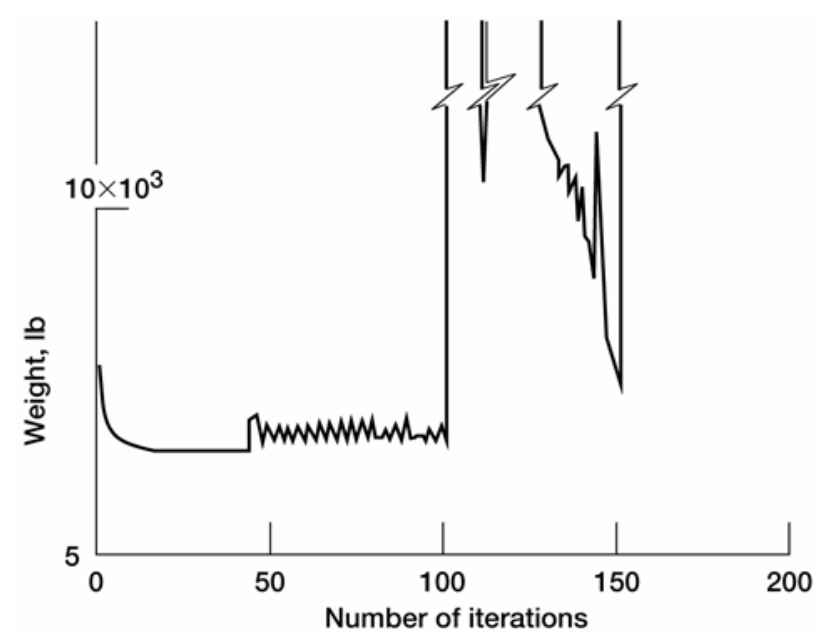

Figure 7(b).--Standard optimization. 


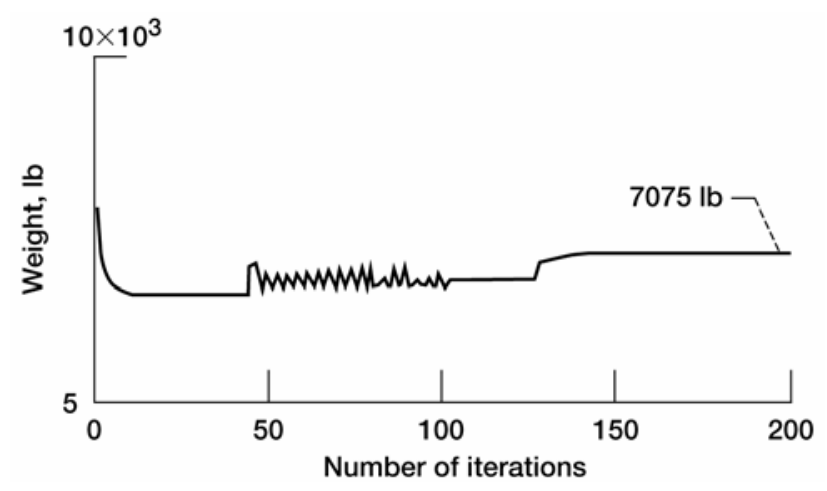

Figure 7(c).-Optimization accounting singularity.

Case (2) converged, while case (1) led to nonconvergence. The utilization of the compatibility concept improved the design optimization of the truss.

3) Design sensitivity. ${ }^{28,32}$

Design optimization via mathematical programming methods of operations research requires the sensitivity matrix. The optimization process is expected to be robust when this matrix is accurate. This issue is examined through the solution of a 60-bar ring problem for minimum weight condition for 180 stress and 4 displacement constraints. The problem is solved using an explicit or closed-form sensitivity matrix, as well as an approximate sensitivity matrix derived from $\mathrm{IFM}^{28}$ (see figure 8). Convergence is reached in 50 reanalysis cycles when approximate sensitivity is used. The closed-form sensitivity required about 25 percent extra re-analysis, or a total of 63 cycles. This unexpected observation is again attributed to compatibility condition. ${ }^{36}$ Singularity is overwhelming with the closed-form sensitivity, but it is diluted when an approximation is used.

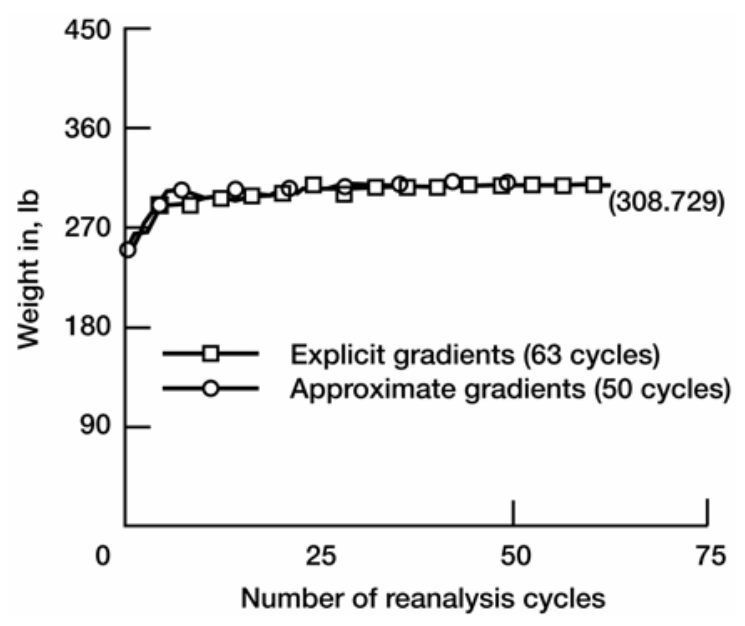

Figure 8.-Convergence for weight for a ring.

In summary, the compatibility condition has considerable influence in the design of indeterminate structures. Ignoring compatibility amounts to a brute-force approach that is not likely to produce a robust design that industry would use. ${ }^{35}$ The infeasibility, singularity, and 
sensitivity in design optimization have been examined for truss-type structures. The same three issues should be examined for flexural members following the approach that has been established for the truss. The behavior study for flexural members is more difficult because stress varies along the member length and depth. Understanding the role of compatibility will provide an insight to behavior of flexural members, leading to a more robust design method. The neglected fully stressed (or utilized) design concept should be revived because it has the potential to become an alternate tool to the design optimization method. It is simple and is practiced in the industry. We have addressed modified fully utilized design (MFUD) ${ }^{27}$ for truss design for stress and displacement constraints. From solution of many design problems, it is observed that properly formulated MFUD can match or quite often exceed the optimization methods. MFUD should be extended to flexural members beginning with continuous beam and then frame with variable depth member; for stress, displacement, and frequency constraints.

\section{Conclusions}

The solid mechanics discipline was deemed complete over a century ago. This judgment is in error because the strain formulation was incomplete both in elasticity and in structures. The strain formulation cannot be ignored because the compatibility concept makes solid mechanics a research discipline. It has significant influence in elasticity, in finite element discrete analysis, and in design optimization. The importance of an accurate stress state can never be overstated. The missing portion of the strain formulation that was not known until recently can control the fidelity of the stress state. A method that circumvents compatibility may work or fail depending on the complexity of the problem. Fidelity of the stress solution can only be guaranteed when it is generated via the Integrated Force Method for finite element analysis and by the completed Beltrami-Michell formulation in elasticity. Indeterminate structures cannot be designed elegantly only through an application of determinate design principles. The compatibility condition that provides an insight to the behavior of indeterminate structure is required for the traditional design as well as for design optimization method. The strain formulation should be addressed simultaneously in elasticity, in finite element discrete analysis, and in design optimization, even though traditionally the three subjects were treated separately. High-speed computers are extremely helpful but cannot replace the information contained in the shaded quarter of the pie diagram in figure 1 . The vacuum created when the researchers knowledgeable in strain formulation retire may be difficult to fill. The premier academic and research institutions should encourage the basic research to complete the solid mechanics discipline.

\section{References}

${ }^{1}$ Patnaik, Surya N., and Hopkins, Dale A., "Stress Formulation in Three-Dimensional Elasticity," NASA/TP-2001-210515, Sept. 2001.

${ }^{2}$ Patnaik, S.N., Kaljevic, I., Hopkins, D.A., and Saigal, S., “Completed Beltrami-Michell Formulation for Analyzing Mixed Boundary Value Problems in Elasticity,” AIAA Journal, Vol. 34, No. 1, 1996, pp. 143-148. 
${ }^{3}$ Panaik, S.N., and Satish, H.G., "Analysis of Continuum Using Boundary Compatibility Conditions of Integrated Force Method,” Computers \& Structures, Vol. 34, No. 2, 1990, pp. 287-295.

${ }^{4}$ Vijayakumar, K., Murty, A.V.K., and Patnaik, S.N., “A Basis for the Analysis of Solid Continua Using the Integrated Force Method,” AIAA Journal, Vol. 26, No. 5, 1988, pp. 628-629.

${ }^{5}$ Patnaik, S.N., and Nagaraj, M.S., "Analysis of Continuum by the Integrated Force Method," Computers \& Structures, Vol. 26, No. 6, 1987, pp. 899-905.

${ }^{6}$ Patnaik, S.N., “The Variational Energy Formulation for the Integrated Force Method,” AIAA Journal, Vol. 24, No. 1, 1986, pp. 129-137.

${ }^{7}$ Patnaik, S.N.,’IFM website for Undergraduate Education”, http:/www.patnaik-ue.org/ifm.

${ }^{8}$ Raju, N.R.B.K., and Nagabhushanam, J., “Nonlinear Structural Analysis Using Integrated Force Method," Sadhana-Academy Proceedings in Engineering Sciences, Vol. 25, Part 4, 2000, pp. 353-365.

${ }^{9}$ Patnaik, S.N., Berke, L., and Gallagher, R.H., “Compatibility Conditions of Structural Mechanics for Finite-Element Analysis,” AIAA Journal, Vol. 29, No. 5, 1991, pp. 820-829; also NASA TM-102413, Jan. 1990.

${ }^{10}$ Patnaik, S.N., Coroneos, R.M., and Hopkins, D.A., "Recent Advances in the Method of Forces: Integrated Force Method of Structural Analysis,” Advances in Engineering Software, Vol. 29, No. 3-6, 1998, pp. 463-474.

${ }^{11}$ Patnaik, S.N., Coroneos, R.M., and Hopkins, D.A., "Dynamic Animation of Stress Modes Via the Integrated Force Method of Structural Analysis,” International Journal for Numerical Methods in Engineering, Vol. 40, No. 12, 1997, pp. 2151-2169.

${ }^{12}$ Constructing Finite Elements for the Integrated Force Method. NASA Tech Briefs, Vol. 21, No. 7, 1997, pp. 70-72.

${ }^{13}$ Kaljevic, I., Patnaik, S.N., and Hopkins, D.A., "Treatment of Initial Deformations in the Integrated Force Method,” Computer Methods in Applied Mechanics and Engineering, Vol. 140, No. 3-4, 1997, pp. 281-289.

${ }^{14}$ Kaljevic, I., Patnaik, S.N., and Hopkins, D.A., "Development of Finite Elements for TwoDimensional Structural Analysis Using the Integrated Force Method,” Computers \& Structures, Vol. 59, No. 4, 1996, pp. 691-706.

${ }^{15}$ Kaljevic, I., Patnaik, S.N., and Hopkins, D.A., "Three-Dimensional Structural Analysis by the Integrated Force Method,” Computers \& Structures, Vol. 58, No. 5, 1996, pp. 869-886.

${ }^{16}$ Patnaik, S.N., Hopkins, D.A., Aiello, R.A., and Berke, L., "Improved Accuracy for FiniteElement Structural-Analysis via an Integrated Force Method," Computers \& Structures, Vol. 45, No. 3, 1992, pp. 521-542.

${ }^{17}$ Patnaik, S.N., Berke, L., and Gallagher, R.H., "Integrated Force Method versus Displacement Method for Finite-Element Analysis,” Computers \& Structures, Vol. 38, No. 4, 1991, pp. 377-407.

${ }^{18}$ Nagabhusanam, J., and Patnaik, S.N., "General-Purpose Program to Generate Compatibility Matrix for the Integrated Force Method,” AIAA Journal, Vol. 28, No. 10, 1990, pp. 1836-1842.

${ }^{19}$ Patnaik, S.N., and Joseph, K.T., "Generation of the Compatibility Matrix in the Integrated Force Method,” Computer Methods in Applied Mechanics and Engineering, Vol. 55, No. 3, 1986, pp. 239-257.

${ }^{20}$ Patnaik, S.N., “The Integrated Force Method versus the Standard Force Method,” Computers \& Structures, Vol. 22, No. 2, 1986, pp. 151-163. 
${ }^{21}$ Patnaik, S.N., and Joseph, K.T., “Compatibility Conditions From Deformation Displacement Relationship,” AIAA Journal, Vol. 23, No. 8, 1985, pp. 1291-1293.

${ }^{22}$ Patnaik, S.N., and Yadagiri, S., "Frequency-Analysis of Structures by Integrated Force Method,” Journal of Sound Vibration, Vol. 83, No. 1, 1982, pp. 93-109.

${ }^{23}$ Patnaik, S.N., and Yadagiri, S., "Design for Frequency by the Integrated Force Method," Computer Methods in Applied Mechanics and Engineering, Vol. 16, No. 2, 1978, pp. 213-230.

${ }^{24}$ Patnaik, S., “An Integrated Force Method for Discrete Analysis,” International Journal for Numerical Methods in Engineering, Vol. 6, No. 2, 1973, pp. 237-251.

${ }^{25}$ Hopkins, D., Halford, G., Coroneos, R., and Patnaik, S., "Fidelity of the Integrated Force Method Solution,” International Journal for Numerical Methods in Engineering, Vol. 55, No. 11, 2002, pp. 1367-1371.

${ }^{26}$ Patnaik, S.N., and Hopkins, D.A., “Optimality of a Fully Stressed Design,” Computer Methods in Applied Mechanics and Engineering, Vol. 165, No. 1-4, 1998, pp. 215-221.

${ }^{27}$ Patnaik, S.N., Gendy, A.S., Berke, L., and Hopkins, D.A., "Modified Fully Utilized Design (MFUD) Method for Stress and Displacement Constraints,” International Journal for Numerical Methods in Engineering, Vol. 41, No. 7, 1998, pp. 1171-1194.

${ }^{28}$ Patnaik, S.N., Hopkins, D.A., and Coroneos, R., "Structural Optimization With Approximate Sensitivities,” Computers \& Structures, Vol. 58, No. 2, 1996, pp. 407-418.

${ }^{29}$ Patnaik, S.N., Guptill, J.D., and Berke, L., "Singularity in Structural Optimization,” International Journal for Numerical Methods in Engineering, Vol. 36, No. 6, 1993, pp. 931-944. ${ }^{30}$ Patnaik, S.N., “Analytical Initial Design for Structural Optimization Via the Integrated Force Method,” Computers \& Structures, Vol. 33, No. 1, 1989, pp. 265-268.

${ }^{31}$ Patnaik, S.N., "Behaviour of Trusses With Stress and Displacement Constraints," Computers \& Structures, Vol. 22, No. 4, 1986, pp. 619-623.

${ }^{32}$ Patnaik, S.N., and Gallagher, Richard H., "Gradients of Behaviour Constraints and Reanalysis Via the Integrated Force Method,” International Journal for Numerical Methods in Engineering, Vol. 23, No. 12, 1986, pp. 2205-2212.

${ }^{33}$ Patnaik, S., and Dayaratnam, P., "Behaviour and Design of Pin Connected Structures,"

International Journal for Numerical Methods in Engineering, Vol. 2, No. 4, 1970, pp. 579-595.

${ }^{34}$ Dayaratnam, P., and Patnaik, S., "Feasibility of Full Stress Design,” AIAA Journal, Vol. 7, 1969, pp. 773-774.

${ }^{35}$ Patnaik, S.N., Coroneos, R.M., Hopkins, D.A., and Lavelle, T.M., "Lessons Learned During Solutions of Multidisciplinary Design Optimization Problems,” Journal of Aircraft, Vol. 39, No. 3, 2002, pp. 386-393.

${ }^{36}$ Patnaik, S.N., Coroneos, R.M., Guptill, J.D., and Hopkins, D.A., "Comparative Evaluation of Different Optimization Algorithms for Structural Design Applications,” International Journal for Numerical Methods in Engineering, Vol. 39, No. 10, 1996, pp. 1761-1774.

${ }^{37}$ Galilei, Galileo, “Dialogues Concerning Two New Sciences,” Northwestern University Press, Evanston, IL, 1950.

${ }^{38}$ Todhunter, I., "A History of the Theory of Elasticity and of the Strength of Materials From Galilei to the Present Time,” University Press, Cambridge, England, 1886.

${ }^{39}$ Love, A.E.H., “A Treatise on the Mathematical Theory of Elasticity,” University Press, Cambridge, England, 1927. 


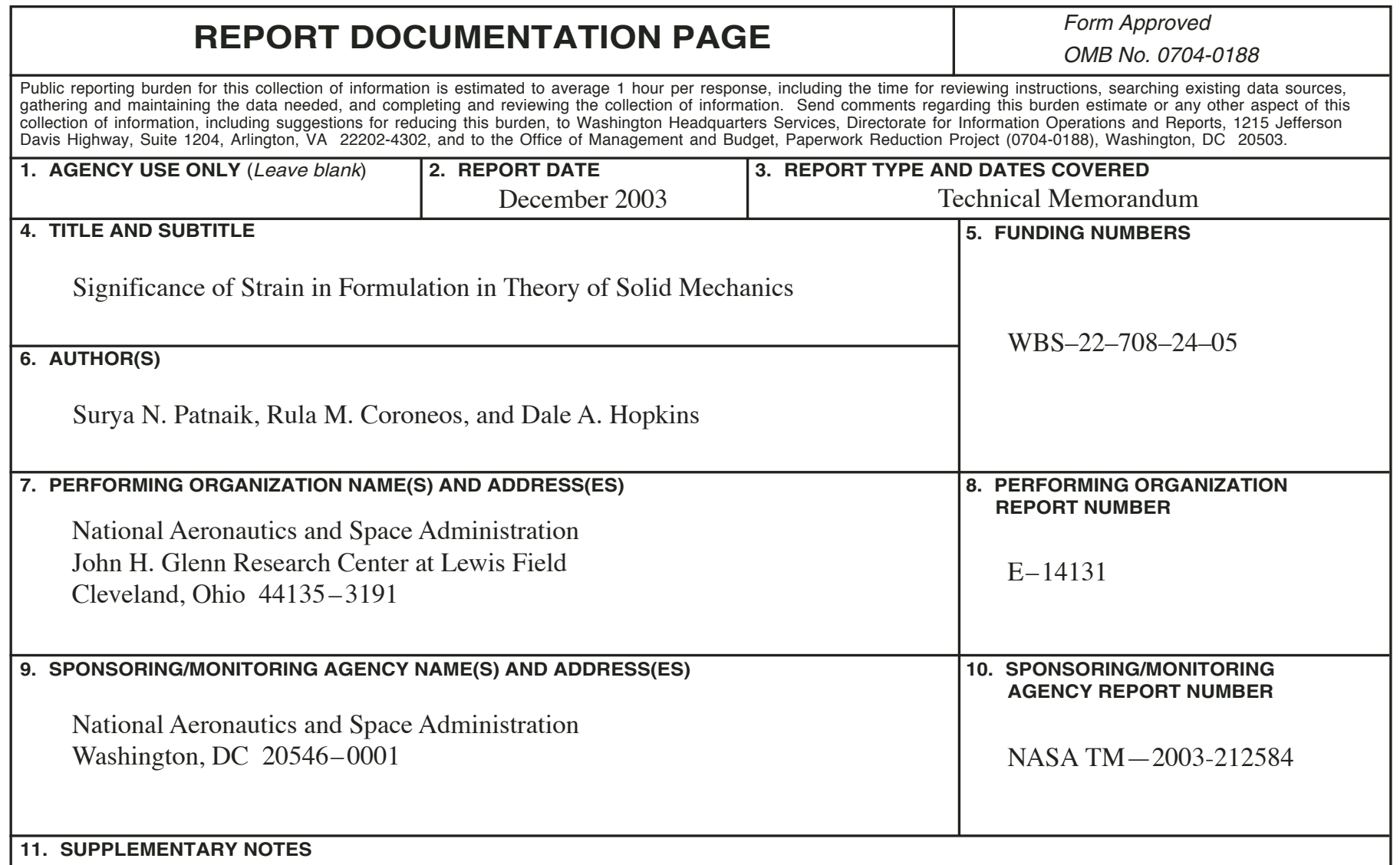

Surya N. Patnaik, Ohio Aerospace Institute, Brook Park, Ohio 44142; and Rula M. Coroneos and Dale A. Hopkins, NASA Glenn Research Center. Responsible person, Surya N. Patnaik, organization code 5930, 216-433-5916.

\begin{tabular}{l|l|l}
\hline 12a. & DISTRIBUTION/AVAILABILITY STATEMENT & \\
Unclassified - Unlimited & Distribution: Nonstandard & \\
Subject Category: 39 & \\
Available electronically at http://gltrs.grc.nasa.gov & \\
This publication is available from the NASA Center for AeroSpace Information, 301-621-0390. &
\end{tabular}

\section{ABSTRACT (Maximum 200 words)}

The basic theory of solid mechanics was deemed complete circa 1860 when St. Venant provided the strain formulation or the field compatibility condition. The strain formulation was incomplete. The missing portion has been formulated and identified as the boundary compatibility condition (BCC). The BCC, derived through a variational formulation, has been verified through integral theorem and solution of problems. The BCC, unlike the field counterpart, do not trivialize when expressed in displacements. Navier's method and the stiffness formulation have to account for the extra conditions especially at the inter-element boundaries in a finite element model. Completion of the strain formulation has led to the revival of the direct force calculation methods: the Integrated Force Method (IFM) and its dual (IFMD) for finite element analysis, and the completed Beltrami-Michell formulation (CBMF) in elasticity. The benefits from the new methods in elasticity, in finite element analysis, and in design optimization are discussed. Existing solutions and computer codes may have to be adjusted for the compliance of the new conditions. Complacency because the discipline is over a century old and computer codes have been developed for half a century can lead to stagnation of the discipline.

\section{SUBJECT TERMS}

Boundary compatibility conditions; Completed Beltrami-Michell formulation; Integrated force method; Primal and dual; Finite element method; Navier's method; Solid mechanics

\begin{tabular}{|c|c|}
\hline $\begin{array}{c}\text { 17. SECURITY CLASSIFICATION } \\
\text { OF REPORT } \\
\text { Unclassified }\end{array}$ & $\begin{array}{c}\text { 18. SECURITY CLASSIFICATION } \\
\text { OF THIS PAGE } \\
\text { Unclassified }\end{array}$ \\
\hline
\end{tabular}

NSN 7540-01-280-5500
15. NUMBER OF PAGES

29

16. PRICE CODE

20. LIMITATION OF ABSTRACT 